\title{
Cerebral autoregulation following minor head injury
}

\author{
Elisabeth C. Jünger, M.D., David W. Newell, M.D., Gerald A. Grant, M.D., Anthony M. Avellino, \\ M.D., Saadi Ghatan, M.D., Colleen M. Douville, B.A., Arthur M. Lam, M.D., Rune Aaslid, Ph.D., \\ and H. Richard Winn, M.D.
}

Department of Neurological Surgery, School of Medicine, University of Washington, Seattle, Washington

The purpose of this study was to determine whether patients with minor head injury experience impairments in cerebral autoregulation. Twenty-nine patients with minor head injuries defined by Glasgow Coma Scale (GCS) scores of 13 to 15 underwent testing of dynamic cerebral autoregulation within 48 hours of their injury using continuous transcranial Doppler velocity recordings and blood pressure recordings. Twenty-nine age-matched normal volunteers underwent autoregulation testing in the same manner to establish comparison values. The function of the autoregulatory response was assessed by the cerebral blood flow velocity response to induced rapid brief changes in arterial blood pressure and measured as the autoregulation index (ARI).

Eight $(28 \%)$ of the 29 patients with minor head injury demonstrated poorly functioning or absent cerebral autoregulation versus none of the controls, and this difference was highly significant $(p=0.008)$. A significant correlation between lower blood pressure and worse autoregulation was found by regression analysis in head-injured patients $(\mathrm{r}=0.6, \mathrm{p}<0.001)$; however, lower blood pressure did not account for the autoregulatory impairment in all patients. Within this group of head-injured patients there was no correlation between ARI and initial GCS or 1-month Glasgow Outcome Scale scores. This study indicates that a significant number of patients with minor head injury may have impaired cerebral autoregulation and may be at increased risk for secondary ischemic neuronal damage.

\section{Key Words * autoregulation * minor head injury * transcranial Doppler ultrasonography}

The cerebral circulation has a capacity to maintain blood flow at a relatively constant level during changes in blood pressure. This phenomenon, known as cerebral autoregulation, is usually observed between a mean arterial blood pressure (MABP) of approximately 50 and $150 \mathrm{~mm} \mathrm{Hg.[14,26]} \mathrm{Cerebral}$ autoregulation can be impaired or absent following severe closed head injury.[4-6,8,9,21,22,25,26] Impairments in autoregulation may contribute by several mechanisms to secondary neuronal injury following head injury. Lowered cerebral perfusion pressure (CPP) caused by arterial hypotension or increased intracranial pressure (ICP) can occur and may cause critical reductions in cerebral blood flow $(\mathrm{CBF})$ to ischemic levels more easily in head-injured patients who have poorly functioning or absent autoregulation. Moreover, sudden increases in blood pressure that may occur in the acute care setting may be more easily transmitted to the microcirculation in the absence of autoregulation and may contribute to secondary hemorrhages and edema.[32] It has also been demonstrated experimentally and in head-injured patients that mannitol is less effective in reducing ICP when autoregulation is 
impaired.[21]

Although information is available about autoregulation in severely head injured patients, there is little or no information about autoregulation in patients with minor or moderate head injury. The purpose of this study was to measure the cerebral autoregulatory response in patients after minor head injury defined by Glasgow Coma Scale (GCS) scores of 13 to 15 and to determine if any patients in this injury severity category experience significant impairments in the autoregulatory response. Dynamic cerebral autoregulation was tested in these patients using noninvasive methods, and the results were compared to the autoregulatory values obtained in the same manner from age-matched volunteers.

\section{CLINICAL MATERIAL AND METHODS}

\section{Study Participants}

This study was approved by the University of Washington Human Subject Review Committee, and written informed consent was obtained from each participant or from the patient's family when appropriate. Twenty-nine unselected patients who had sustained minor head injury, defined by GCS scores of 13 to 15, and who were admitted to Harborview Medical Center over a 5-month period for acute care of their head injuries were included in the study. Computerized tomography (CT) scans were obtained in all patients within hours of their arrival. Patients were treated according to a standard minor head injury treatment regimen that included bed rest, analgesic medications (including low-dose morphine in some patients), and intravenously administered crystalloid solutions. Some of the patients underwent placement of an ICP monitor (fiberoptic subarachnoid catheters; Camino Laboratories, San Diego, CA) if CT scans indicated hemorrhages or contusions that were judged to place the patients at risk for secondary deterioration or if patients were undergoing early surgical procedures. Patients were assigned GCS scores within 8 hours of hospital admission after elimination of possible confounding effects of any early sedation or paralytic drugs that may have been administered. The GCS scores were also recorded at the time of testing in each individual and were found to be unchanged from the admission scores. All patients underwent autoregulation testing within 48 hours of head injury. Outcome at 1 month was assessed by notes from clinic visits or by telephone interviews with patients or relatives, according to the Glasgow Outcome Scale (GOS) score[11,12] as follows: 5, good recovery; 4, moderate disability; 3 , severely disabled; 2 , vegetative; and 1 , dead.

Twenty-nine age-matched healthy volunteers were also included in the study. The age range of the patients and the volunteers was between 18 and 72 years. Before being entered into the study all patients underwent a cerebral CT scan, and all patients and normal volunteers were screened for extracranial carotid artery disease by Doppler ultrasonography and for intracranial vascular pathology by transcranial Doppler (TCD) ultrasonography. Exclusion criteria were known cardiovascular or peripheral vascular disease, carotid artery or intracranial stenosis, and vasospasm following traumatic subarachnoid hemorrhage. Patients with significant leg injuries were also excluded. In each participant, both middle cerebral arteries (MCAs) were identified by TCD ultrasonography according to standard criteria. The transducers were then fixed in place by a head band, and CBF velocities were continuously monitored and recorded (Multidop X; DWL Corp., Sipplingen, Germany). The MABP was noninvasively measured over one radial artery by use of a continuous tonometric blood pressure monitor (N-Cat N-500; Nellcor Corp., Hayward, CA), and the analog output was continuously recorded using the transducer. In spontaneously breathing patients and normal volunteers, end-tidal $\mathrm{CO}_{2}$ was also measured using nasal prongs connected to a $\mathrm{CO}_{2}$ monitor (Datex 223; Puritan Bennett Corp., Tewksbury, MA). The output 
data were recorded using the transducer.

Testing was performed while participants were supine with an approximately 10 to 20š inclination of the upper body. The reference point for the blood pressure recordings was 5 to $10 \mathrm{~cm}$ below the external auditory meatus in all patients and normal volunteers. Large blood pressure cuffs were placed around both thighs and inflated to 20 to $40 \mathrm{~mm} \mathrm{Hg}$ above the systolic blood pressure for 3 minutes. Releasing the cuffs caused a sharp but moderate transient drop in systemic blood pressure. Drops in MABP of more than $12 \mathrm{~mm} \mathrm{Hg}$ were considered a sufficient autoregulatory stimulus. The test was repeated several times (three-eight) in each participant, and three to four responses were averaged to give the final response for each MCA perfusion territory.

Calculations were performed on-line to assure the acquisition of at least three technically perfect measurements and off-line for the final evaluation using the time-averaged mean velocities of the maximum velocity outlines of the Doppler spectrum and MABP. Values for each MCA were analyzed separately, and an overall autoregulation index (ARI) was calculated by averaging both sides.

\section{Methods for Calculating Dynamic Autoregulatory Response}

A detailed description of the methodology used to calculate the dynamic autoregulatory response has been published elsewhere, including the equations describing the computer model used to obtain the ARI.[34] Briefly, to calculate the dynamic autoregulatory response, a disturbance or error signal is introduced into the system. This disturbance is the rapid drop in CBF caused by the sudden drop in blood pressure induced by deflating the leg cuffs. The autoregulatory response is activated, and the normal response is to cause a rapid reduction in the overall cerebrovascular resistance (CVR) to restore blood flow to the resting level. The ARI is calculated from a computer model that considers the latency and overall effectiveness of this response for any given change in blood pressure. The changes in blood pressure and $\mathrm{CBF}$ velocity values in the proximal MCAs immediately before and after the cuff release are used to calculate an ARI that reflects relative changes in blood flow through the MCA caused by the change in distal CVR per second, relative to the change in MABP. The TCD ultrasonography therefore monitors the relative change in blood flow through the inflow vessels (bilateral MCAs) during the autoregulatory response to a transient drop in blood pressure. A hypothetical curve of the CBF velocity values is created based on the MABP immediately prior to the drop and during the 30 seconds thereafter. If there were no autoregulation, the relative changes in CBF velocity would parallel the changes in MABP and the ARI would be zero. The computer calculates nine other possible responses to the given change in MABP based on a stepwise improvement in the autoregulatory response.[34] The actual response is examined and the "best fit" with the model (the lowest standard error of the mean of the difference between the model and the actual response) is taken as the ARI. The higher the ARI, the more rapid and efficient is the autoregulatory response.

\section{Statistical Analysis}

Results were analyzed using the following statistical methods: chi-square and McNemar's test for age-matched chi-square values, Fisher's exact test, Student's t-test, the Mann-Whitney U-test, and regression analysis. Differences were considered significant at the $\mathrm{p}<0.05$ level. Values are expressed as means \pm standard deviation (SD). 
DIAGNOSIS ON CT SCAN IN 29 PATIENTS WITH MINOR HEAD INURYA

\begin{tabular}{lc}
\hline \hline \multicolumn{1}{c}{ Diagnosis on CT } & $\begin{array}{c}\text { No. of } \\
\text { Patierts }\end{array}$ \\
\hline normal (includes facial \& skull fractures, scalp hematom as) & 9 \\
traumatic SAH & 3 \\
contusions & 7 \\
SDH & 3 \\
EDH & 1 \\
multiple lesions & 6 \\
traumatic SAH, contusion & 1 \\
traumatic SAH, contusions, IVH & 1 \\
shear injury, traumatic SAH, intracranial air pocket & 1 \\
SDH, contusions & 3 \\
tilat shear injuries, IVH & 1 \\
total & 29 \\
\hline
\end{tabular}

${ }^{\star} \mathrm{EDH}=$ epidural hematom $\mathrm{a} ; \mathrm{IVH}=$ intratentricular hemorhage; $\mathrm{SAH}=$ subarachnoid hemorrhage; $\mathrm{SDH}=$ subdural hematoma.

\section{RESULTS}

The diagnoses of patients based on CT scans are shown in Table 1. Nine of 29 patients had normal intracranial CT scans. The mean GCS score following stabilization of the patients in the emergency room was 14.7. With the exception of heart rate, which was higher in patients, demographic data in both groups were not significantly different, as shown in Table 2.

\begin{tabular}{|c|c|c|c|}
\hline DEMOGRA & $\begin{array}{r}\text { TABL } \\
\text { IN NORMAL YOL } \\
\text { MINOR HEA }\end{array}$ & $\begin{array}{l}2 \\
\text { UTEERS AND PATIENTS } \\
\text { NWRV }\end{array}$ & \\
\hline Parameter & Volunteers & Head-1niured Patients & $p$ Value \\
\hline no. of participants & 29 & 29 & \\
\hline $\begin{array}{l}\text { sex } \\
\text { male }\end{array}$ & 18 & 23 & \\
\hline female & 11 & & \\
\hline $\begin{array}{l}\text { age (yrs) } \\
\mathrm{GCS} \text { sonre }\end{array}$ & $38 \pm 16$ & $38 \pm 16$ & 0.92 \\
\hline $\begin{array}{l}\text { GCS soore } \\
\text { MA EP at rest }\end{array}$ & $85 \pm 10$ & $\begin{array}{c}4.8 \pm 0.0 \\
89 \pm 18\end{array}$ & 0.33 \\
\hline $\begin{array}{l}\text { heart rate at rest } \\
\text { It } \mathrm{CBF} \text { welocity }\end{array}$ & $\begin{array}{l}66 \pm 9 \\
61 \pm 14\end{array}$ & $\begin{array}{l}78 \pm 15 \\
61 \pm 16\end{array}$ & $\begin{array}{l}0.0005 \\
0.96\end{array}$ \\
\hline rt CBF welodity & $60 \pm 13$ & $60 \pm 17$ & 0.97 \\
\hline $\begin{array}{l}\text { end-tidal } C C Q \\
\text { (26 participants) }\end{array}$ & $33 \pm 5$ & $33 \pm 6$ & 0.98 \\
\hline
\end{tabular}

The MABP at rest was not significantly different between patients and normal volunteers. The magnitude of the blood pressure drop was slightly less in the patients than in the volunteers; however, this should not affect the results significantly because the ARI calculation takes into account the magnitude of the blood pressure drop. The MABP immediately after the release of the blood pressure cuffs was slightly higher in patients than in normal volunteers (Table 3). 
TABLE 3

HEMODYNAMK YLUES FOUND DURING AUTOREGULATION TESTING IN PATIENTS WITH MINOR HEAD INWURV AND NORMAL YOLUNTEERS

\begin{tabular}{lccl}
\hline \hline \multicolumn{1}{c}{ Hemodynamics } & Volunteers & Head- niư ed Patierts & p Value \\
\hline MAEP drop (mm HG) & $22 \pm 5.0$ & $17 \pm 5.0$ & 0.002 \\
MAEP postdrop & $64 \pm 10$ & $72 \pm 16$ & 0.03 \\
(mm HG) & $4.6 \pm 1.0$ & $3.9 \pm 2.0$ & 0.098 \\
left MCA ARI & $4.8 \pm 1.0$ & $4.1 \pm 2.2$ & 0.1 \\
right MCA ARI & $4.7 \pm 1.0$ & $4.0 \pm 2.1$ & 0.1 \\
mean ARI &
\end{tabular}

"Statisticall y significant. Probability walues mere calculated using Student's ttest (two-tailed, nonpaired). The category MABP drop measures the magnitude of the blood pressure change during the autoregulation test, and MABP postdrop measures the MABP im mediately after blood pressure drop.

There was no significant difference in autoregulation values between the right and left MCAs within either patient $(\mathrm{p}=0.15)$ or control groups $(\mathrm{p}=0.12)$ by two-tailed paired $\mathrm{t}$-test. Regression analysis also indicated close correlations between the ARI values in the right and left hemispheres in normal volunteers $(\mathrm{y}=0.83+0.87 \mathrm{x}, \mathrm{r}=0.88, \mathrm{p}<0.0001)$ and in patients $(\mathrm{y}=20.15+1.08 \mathrm{x}, \mathrm{r}=0.96, \mathrm{p}<$ $0.0001)$. We therefore assigned one ARI value to each participant.

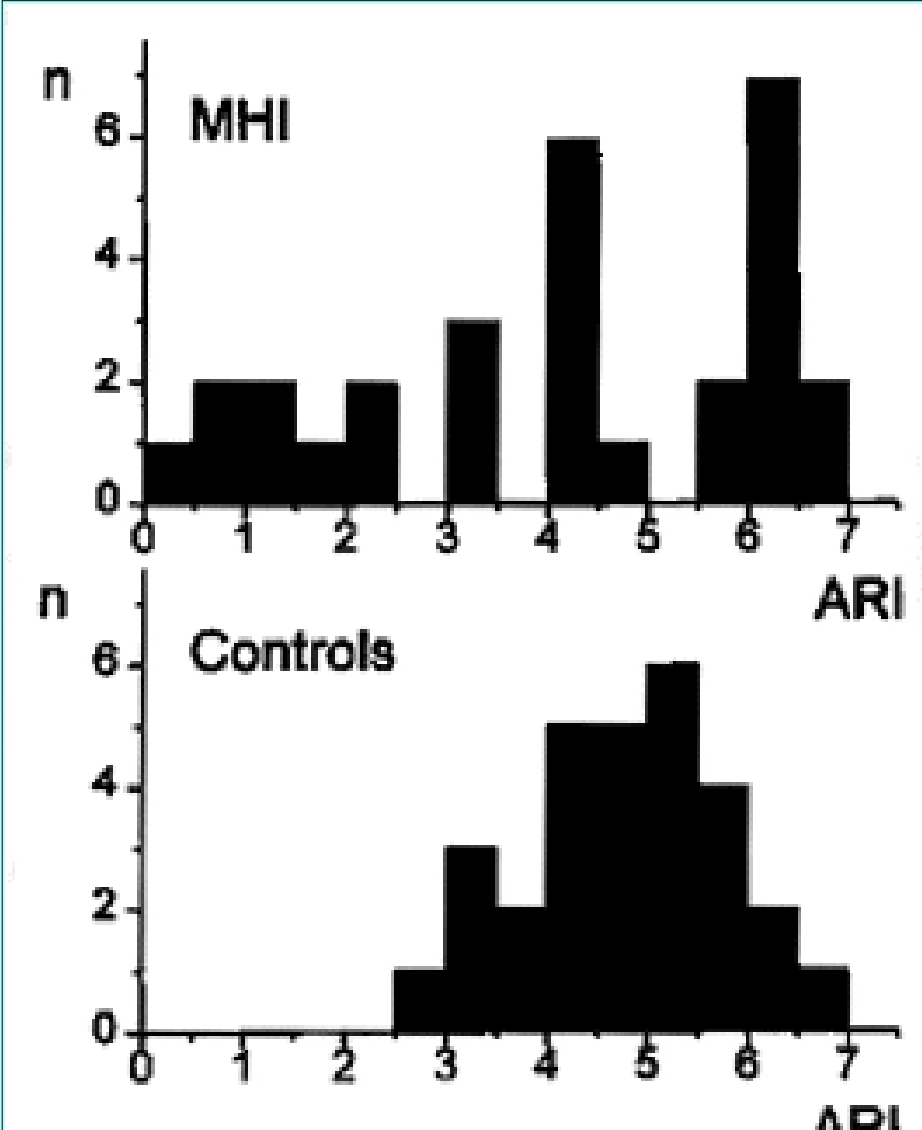

Fig. 1. Histograms showing the distribution of ARI grades in head-injured patients (upper) and normal volunteers (lower). Note that in the volunteers the ARI values are normally distributed with a mean value of $4.7 \pm 1$. The mean ARI value is lower in the head-injured group $(4 \pm 2$.). The values in the head-injured patients appear to be distributed into two groups including a majority with intact autoregulation and a subgroup with impaired or absent autoregulation.

The mean ARI in the head-injured patients as a group was lower than in controls, but not significantly different by two-tailed t-test or the Mann-Whitney U-test (Table 3). Using a one-tailed t-test, however, the group ARI values observed in the head-injured patients were significantly lower compared to controls $(p=0.048)$. The main reason for the nonsignificant difference between mean ARI values in volunteers and head-injured patients according to the other tests is the fact that the ARI head-injured patient population behaved as two groups, one with normal values and a subgroup with significantly lower ARI values, as shown in Fig. 1. The SD was therefore two times as high in the patients as in normal volunteers, thus making the group comparisons less significant. However, when the volunteers and patients were divided into two groups, those with intact and impaired autoregulation, significantly more head-injured patients had impaired autoregulation than did volunteers (Table 4). 


\begin{tabular}{|c|c|c|c|}
\hline \multicolumn{4}{|c|}{$\begin{array}{c}\text { TABLE } 4 \\
\text { DISTRIBUTION OF ARI IN PATIENTS WITH MINOR HEAD IN.URY } \\
\text { AND IN YOLUNTEERS }\end{array}$} \\
\hline \multirow[b]{2}{*}{ Group } & \multicolumn{3}{|c|}{ No. of Parlicipants } \\
\hline & $A P I=2.5$ & $A R \mid<2.5$ & Total \\
\hline $\begin{array}{l}\text { wolunteers } \\
\text { head-injured patients } \\
\text { total }\end{array}$ & $\begin{array}{l}29 \\
21 \\
50\end{array}$ & $\begin{array}{l}0 \\
8 \\
8\end{array}$ & $\begin{array}{l}29 \\
29 \\
58\end{array}$ \\
\hline
\end{tabular}

"Acoording to the chi-square test for unpaired data $(p=0.002)$ and the chisquare test for age-matched groups (McNemar's) $(p=0.008$ ).

Plotted as a histogram, the ARI values in normal volunteers formed a nearly perfect normal distribution with all but one value within two SDs from the mean ( $4.7 \pm 1$ [Fig. 1]). None of the volunteers displayed an ARI below 2.5, which equals a static, or steady-state, autoregulation value of 40\%.[34] This value would imply that if the blood pressure were changed pharmacologically, the CBF would only show a $40 \%$ correction toward the resting value. However, patients with minor head injuries constituted two groups: 21 patients with normal autoregulation (ARI $>=2.5$ ) and eight with impaired or exhausted autoregulation (ARI < 2.5). Using an ARI of 2.5 as the dividing point, the difference of ARI distribution in normal volunteers and in patients with minor head injuries was highly significant on the chi-square test ( $\mathrm{p}=0.002 ; \mathrm{p}=0.008$ using McNemar's test for age-matched comparisons) (Table 4).

\begin{tabular}{|c|c|c|c|}
\hline \multicolumn{4}{|c|}{$\begin{array}{c}\text { TABLE } 5 \\
\text { COMPARISON BETWEEN } 29 \text { PATIENTS WITH MINOR HEAD IN,URV AND NORMAL OR } \\
\text { IMPAIRED CEREBRAL AUTOREGULATIONネ }\end{array}$} \\
\hline Variatle & $\mathrm{APl}=2.5$ & $\Delta P \mid<2.5$ & p Value \\
\hline $\begin{array}{l}\text { s) } \\
\text { core on admission } \\
\text { d inter ientions } \\
\text { ial cT scan } \\
\text { velocity } \\
\text { velocity } \\
\text { (resting) (mm Hg) } \\
\text { op MA EP (mm Hg) } \\
\text { op (mm Hg) }\end{array}$ & $\begin{array}{c}21 \\
5.0 \pm 1.3 \\
39 \pm 18 \\
14.8 \pm 0.4 \\
3 \\
13 \\
57 \pm 15 \\
57 \pm 14 \\
95 \pm 17 \\
78 \pm 15 \\
17 \pm 6 \\
4.9 \pm 0.4\end{array}$ & $\begin{array}{c}8 \\
1.3 \pm 0.8 \\
34 \pm 13 \\
14.5 \pm 0.5 \\
1 \\
7 \\
71 \pm 17 \\
67 \pm 24 \\
74 \pm 9 \\
57 \pm 9 \\
17 \pm 3 \\
4.9 \pm 0.4\end{array}$ & $\begin{array}{l}0.43 \dagger \\
0.24 \dagger \\
1.0 \ddagger \\
0.371 \ddagger \\
0.07 \dagger \\
0.30 \dagger \\
0.0003 \dagger \\
0.0001 \dagger \\
0.58 \dagger \\
1.0 \dagger\end{array}$ \\
\hline \multicolumn{4}{|c|}{$\begin{array}{l}\text { "Statistically significant difference. Abtreviations: ABP drop = magnitude of } \\
\text { the blood pressure change during the autoregulation test; MABP (íesting) = } \\
\text { MA EP before blood pressure drops; postdrop MMBAP = MAB EP im mediately after } \\
\text { thood pressure drop. } \\
t \quad \text { Student's t-test. } \\
\ddagger \quad \text { Fisher's exact test. }\end{array}$} \\
\hline
\end{tabular}

We also examined the two groups of patients (those with intact and those with impaired autoregulation) to detect possible differences in the test conditions or physiological variables and to determine if a difference in these variables could account for the differences in ARI values found (Table 5). Resting MABP in the subgroup of patients with impaired autoregulation was lower than that seen in normal volunteers and also significantly lower than in patients with normal ARI values $(p=0.0003)$. As Fig. 2 illustrates, a regression analysis in normal volunteers revealed no correlation between MABP and ARI, whereas we observed a significant correlation between MABP and ARI $(p=0.0008)$ in head-injured 
patients. The blood pressure drop from the test was similar in subgroups of patients with impaired (17 \pm $3 \mathrm{~mm} \mathrm{Hg})$ and those patients with normal autoregulation $(17 \pm 6 \mathrm{~mm} \mathrm{Hg}, \mathrm{p}=0.58)$ and therefore should not have influenced the results. The MABP during the autoregulation test dropped to $57 \mathrm{~mm} \mathrm{Hg}$ in patients with impaired autoregulation and to $78 \mathrm{~mm} \mathrm{Hg}$ in patients with normal autoregulation ( $\mathrm{p}=$ 0.0001). The main cause of this difference was a lower resting MABP before the test in patients with impaired autoregulation.

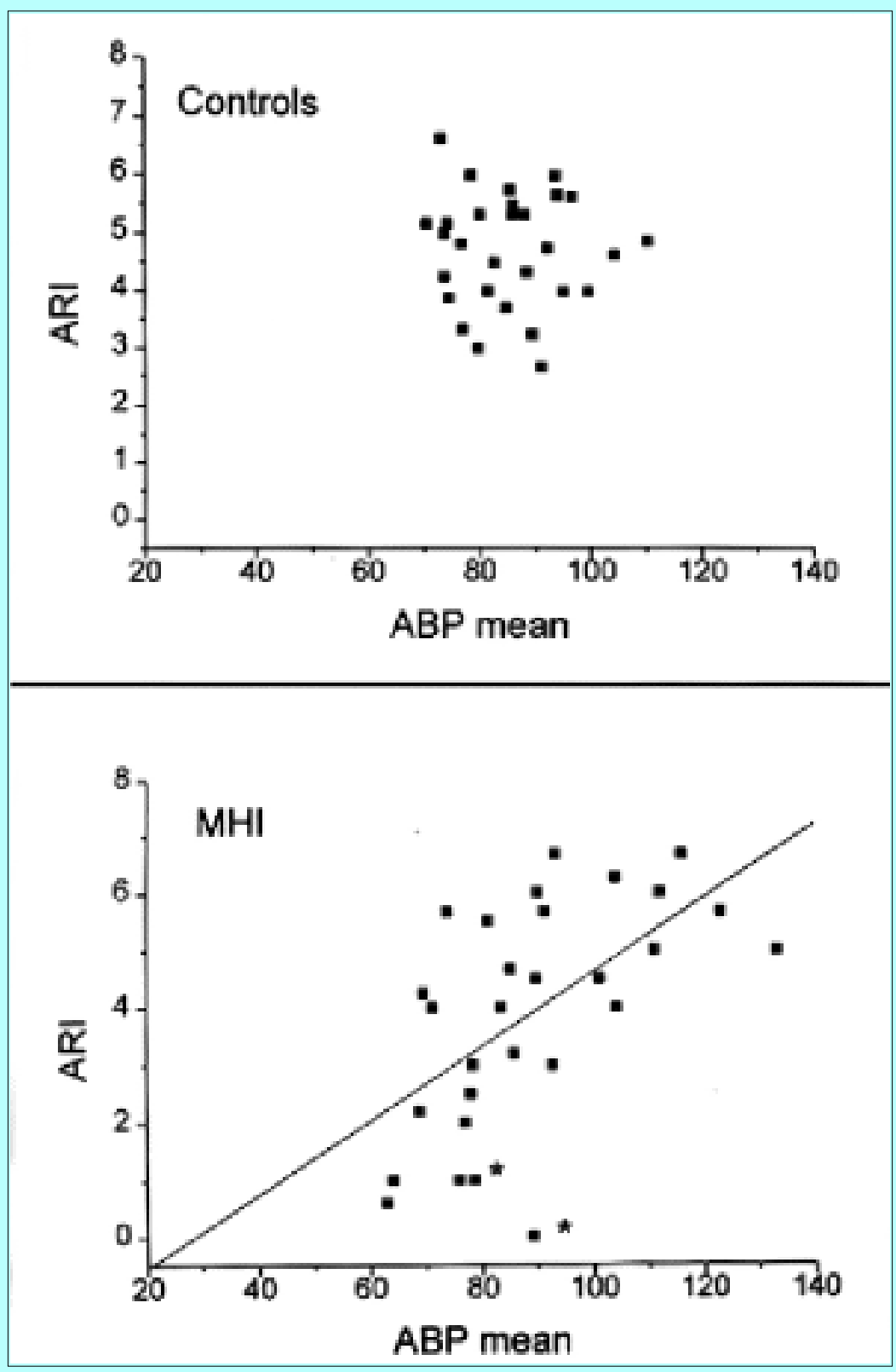

Fig. 2. Scatterplots showing regression analysis between resting MABP and ARI. Upper: Analysis in normal volunteers indicating no significant relationship between the two variables $(\mathrm{r}=-0.05, \mathrm{p}=0.78)$. Lower: Analysis in head-injured patients indicating a significant association between lower blood pressure and impaired autoregulation $(\mathrm{y}=-1.8$ $+0.06 \mathrm{x}, \mathrm{r}=0.59, \mathrm{p}<0.001$ ). Several patients (asterisks) did not follow the trend and had low ARI values despite a seemingly adequate blood pressure. $\mathrm{MHI}=$ minor head injury.

This analysis suggests that lower blood pressure contributes to impaired autoregulation in some patients; however, lower MABP does not account for the most severely impaired ARI values (labeled with asterisk in Fig. 2). Because we did not obtain CPP values in these patients with apparently adequate 
MABP at the time of testing, we cannot be sure that CPP was not low. In one patient with severely impaired autoregulation ( $\mathrm{ARI}=1)$ and normal blood pressure $(\mathrm{MABP}=76)$, the ICP was monitored during testing and was not significantly elevated (ICP $=10)$. In another patient with an ARI of less than 1, the MABP was $78 \mathrm{~mm} \mathrm{Hg}$ and the ICP was monitored during the 24-hour interval prior to testing and was not elevated (ICP 10-12 $\mathrm{mm} \mathrm{Hg}$ ). This patient was readmitted to the hospital for eye surgery, and we were able to follow changes in the ARI within 2 weeks. Whereas autoregulation was severely impaired on Days 2 and 4 postinjury, it was in the normal range on Day 14. However, MABP was identical on Days 4 and 14 (Fig. 3). These results indicate that in some of these patients the low ARI cannot be entirely accounted for by low CPP.

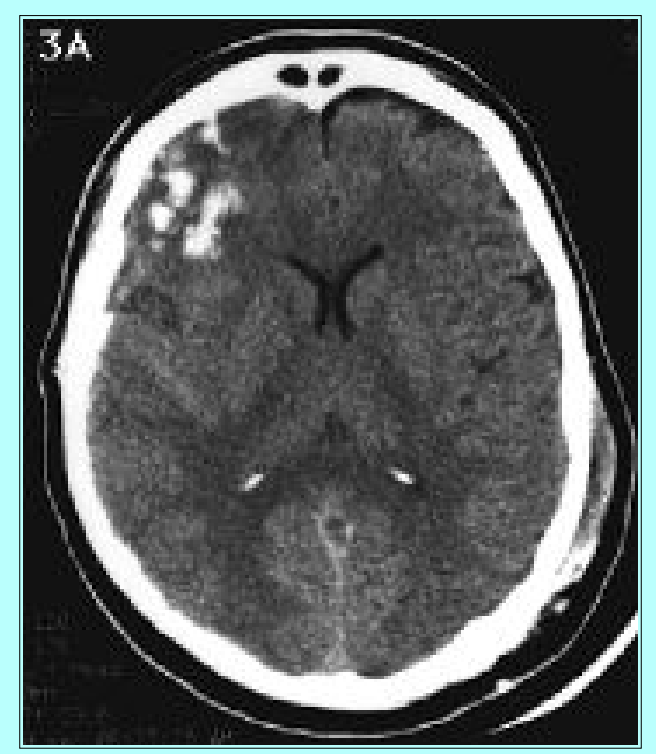

Fig. 3. A: Computerized tomography scan demonstrating a frontal contusion in a patient with severely impaired autoregulation. B: Graph depicting the ARI and blood pressure values over time in the same patient. The ARI values remained low on Days 2 and 4 postinjury and returned to the normal range on Day 14 despite minimal changes in blood pressure between the three evaluations. This patient's ICP was also monitored until just before the initial autoregulation testing on Day 2; the ICP was not elevated (ICP 10-12 mm $\mathrm{Hg}$ during a 24-hour interval prior to testing). 


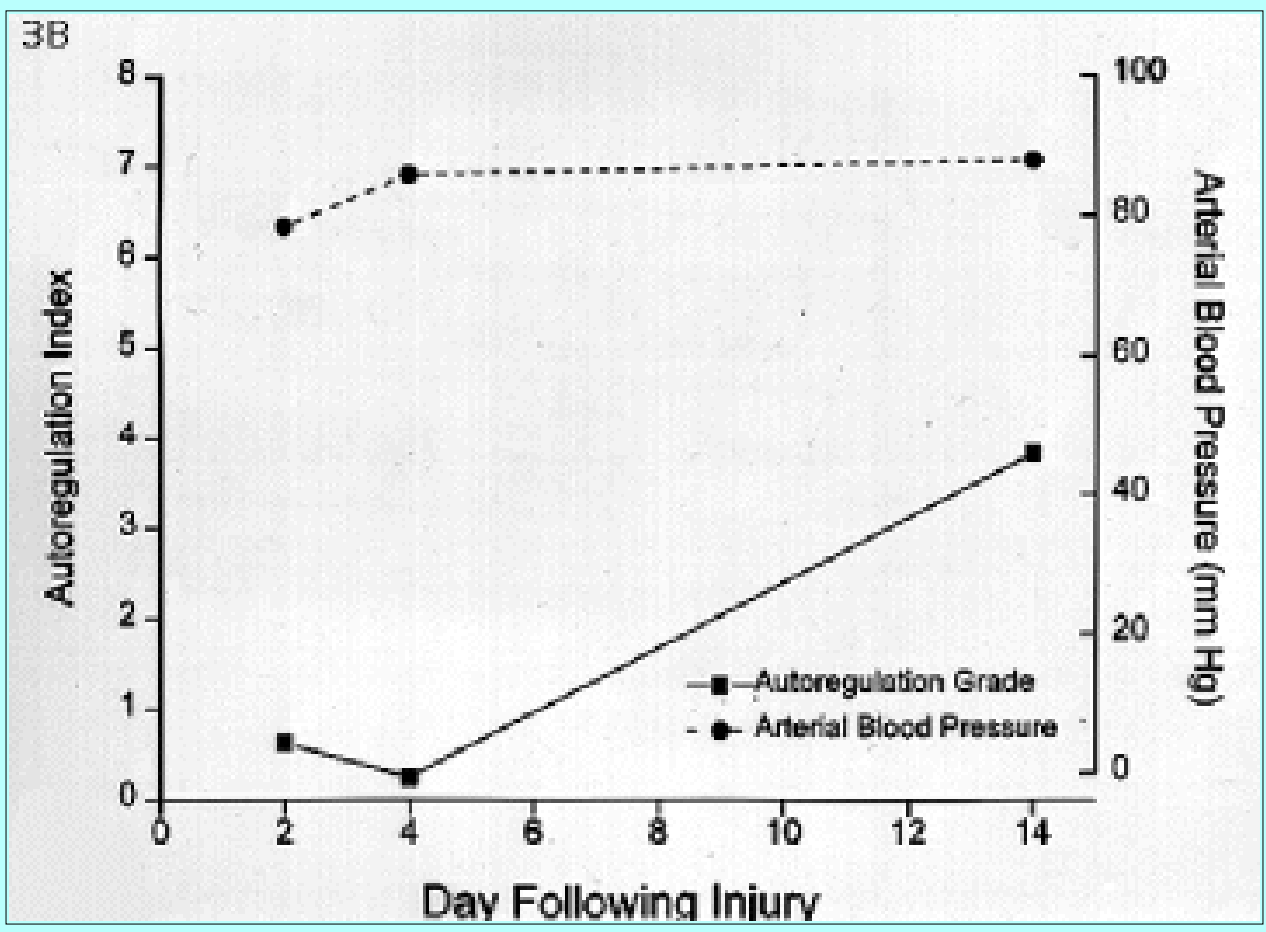

We also examined the relationship in the patient group between ARI and clinical parameters including admission GCS scores, surgery (Table 6), and 1-month GOS scores. The relationship between the initial GCS score and ARI is shown in Fig. 4. There was no correlation between the two; however, all patients had GCS scores of 14 or 15. Differences in medications between the patients with intact and impaired autoregulation also did not appear to account for the differences in the ARI. The only apparent medication difference in the two groups was the more frequent administration of morphine in patients with impaired ARI (seven of eight) than in those with intact ARI (11 of 21); however, the difference was not statistically significant ( $\mathrm{p}=0.9$ by chi-square test).

\begin{tabular}{|c|c|c|c|}
\hline \multicolumn{4}{|c|}{$\begin{array}{c}\text { TABLE } 6 \\
\text { SUMMRY OF FOUR PATIENTS WHO UNDERWENT SURGERY WITH N } \\
1 \text { WEEK POSTNUR'太 }\end{array}$} \\
\hline $\begin{array}{l}\mathrm{GCS} \\
\text { Sc ore }\end{array}$ & $\begin{array}{l}\text { Indication } \\
\text { for Surgery }\end{array}$ & Intervertion & $A R$ \\
\hline $\begin{array}{l}14 \\
15 \\
15 \\
15\end{array}$ & $\begin{array}{l}\mathrm{SDH} \\
\mathrm{SDH} \\
\text { gun shot } \\
\text { mound } \\
\text { small SDH }\end{array}$ & $\begin{array}{l}\text { It craniotomy, evaduation of SDH } \\
\text { rt craniotom y' evacuation of SDH } \\
\text { rt craniotomy, e vacuation of tem poral lobe } \\
\text { contusion, decom pression of optic nerve } \\
\text { craniotom y for evacuation of small SDH }\end{array}$ & $\begin{array}{l}5.5 \\
6.7 \\
0.9\end{array}$ \\
\hline & & na. & \\
\hline
\end{tabular}

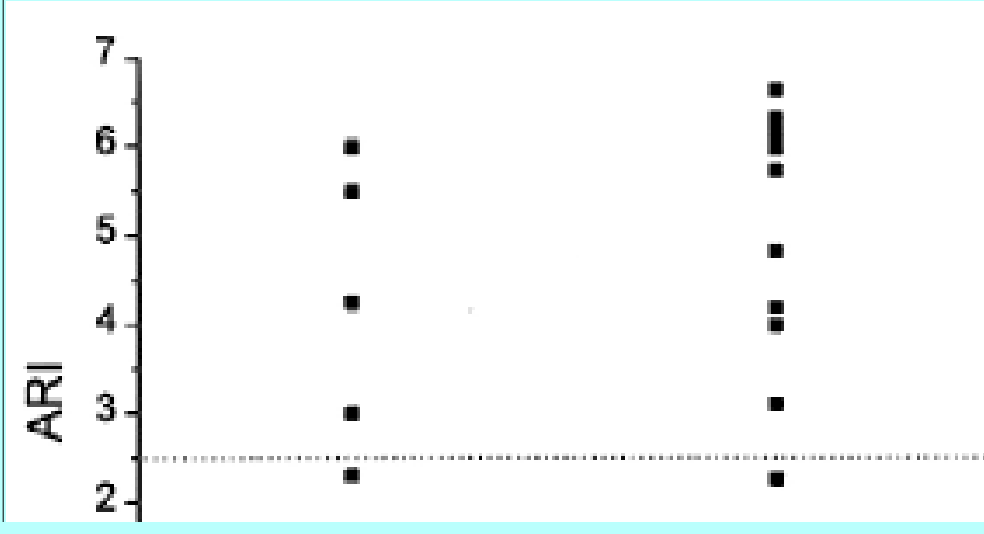

Fig. 4. Scatterplot illustrating the relationship between initial GCS score and ARI and also showing the distribution of GCS scores within the head-injured group.

Clinical outcome after 1 month assessed by GOS also did not correlate with ARIs assessed within the first 48 hours. As expected, all patients had a favorable outcome (good recovery or moderate disability) 


\section{DISCUSSION}

GCS day 1

The results of this study indicate that a significant number of patients (eight [28\%] of 29) can have severely impaired or absent cerebral autoregulation following minor head injury compared to age-matched controls. This group of patients, who have poorly functioning autoregulation, may be uniquely vulnerable to ischemic brain damage if reductions in CPP occur after their head injury, during the time in which their autoregulation is impaired. They may be at increased risk of neurological deterioration from brain ischemia during surgical procedures, when blood pressure fluctuations are known to occur, especially if hypotension is present.

The method used to assess autoregulation in this study was the dynamic autoregulatory response of the relative blood flow changes in both MCAs measured using TCD sonography. This response was elicited by a rapid but moderate drop in blood pressure induced by the release of the large leg cuffs. This method was first described by Aaslid, et al.,[1] and its validity has subsequently been confirmed by multiple studies.[2,13,16,23,24,33,34] It has been demonstrated that during short recording periods relative changes in MCA velocity are a valid estimation of relative volume flow changes in response to both rapid and slow changes in MABP.[2,13,16,24] To measure the effectiveness of the autoregulatory response the change in CVR can be estimated in response to a slow change in MABP (the static or steady-state autoregulatory response) or to rapid changes in blood pressure (the dynamic autoregulatory response).[34] We have previously demonstrated that impairment of autoregulation induced by high-dose anesthetic agents causes a similar decrease in the static and dynamic autoregulatory responses in normal volunteers.[33,34] We assumed therefore that the changes observed in the dynamic autoregulatory response in these head-injured patients also reflect impairment in the static or steady-state autoregulatory response.

There has been no standardization of the definitions of "intact" or "absent" cerebral autoregulation after head injury.[6,9,21,22,25,26] Muizelaar and colleagues[21,22] evaluated autoregulation in head-injured patients by obtaining CBF values and either raising or lowering MABP to a new steady state and repeating the $\mathrm{CBF}$ measurement. They defined intact autoregulation as the $\bullet \% \mathrm{CPP} / \% \bullet \mathrm{CVR} 3 / 42$ following the change in MABP, where CVR $=\mathrm{CPP} / \mathrm{CBF}$. This would correspond to a $50 \%$ response or $50 \% \mathrm{CBF}$ correction in response to the blood pressure change in our static (steady-state) method or an ARI value approximately equal to 2.8.[34] Our cutoff between intact and impaired autoregulation is therefore slightly lower than these previously reported values.

The precise cause of the impairment of autoregulation in our patients is uncertain; however, a correlation between MABP and autoregulation grade was found, suggesting that low CPP may have contributed to the autoregulatory impairment in some patients. However, there were also patients who experienced reduced autoregulation despite an adequate blood pressure (Fig. 2) and also some with reduced autoregulation who had a documented CPP that was not lower than that normally required for autoregulation (see Results). Another possible cause of impaired autoregulation after head injury is vasospasm. However, these patients were evaluated within 48 hours of injury, usually before the onset of vasospasm, and none displayed elevated MCA velocities.

It is well known that the autoregulatory response becomes less effective at lower CPP levels.[14,26] The initial work by Lassen[14] demonstrated that as MABP decreased, CBF decreased passively below an 
MABP of 50 to $60 \mathrm{~mm} \mathrm{Hg}$ (referred to as the lower limit of autoregulation). Therefore, even patients who have an intact autoregulatory response above this limit will lose autoregulation if the ICP, the MABP, or a combination of the two factors reduces the CPP below the level at which autoregulation functions normally. Miller, et al.,[19] demonstrated that increasing ICP by inflation of a microballoon in the intracranial space of dogs abolished the autoregulatory response when the CPP was reduced below 40 $\mathrm{mm} \mathrm{Hg}$. However, after one or two balloon inflations, or preceding arterial hypotension, autoregulation was impaired despite a restoration in CPP, indicating that ischemia or other processes damaged the autoregulatory response. Lewelt, et al.,[15] demonstrated that the autoregulatory response could also be impaired after fluid percussion injury, even though CPP was in the normal range. These results also indicate that a mechanism other than CPP reduction can be responsible for impaired autoregulation after head injury.

One phenomenon that may occur after head injury is that the "autoregulatory curve" could be shifted to the right, which would imply that a higher CPP is needed for the autoregulatory response to function properly. It is of interest to note that in our study there was no difference in the resting MABP values between control individuals and patients. However, although there was no correlation between MABP and ARI in volunteers, there was a strong correlation between MABP and ARI in the head-injured patients. These data indicate that despite the fact that the resting MABP was the same in both groups, autoregulation was worse in the head-injured patients than in the volunteers at the lower blood pressure values. We did not increase the CPP in our patients to determine if this would improve impaired autoregulation after head injury, but studies of the effect of increased CPP and other methods to improve impaired autoregulation in humans after head injury are needed.

One of the important implications of these results is that even patients with minor head injuries may be at increased risk for secondary ischemic neuronal damage during an as yet undefined period following their head injury. Studies using experimental models of head injury have demonstrated that even after minor and moderate injury levels the brain appears to have an increased sensitivity to subsequent ischemic damage. $[7,10]$ The exact mechanisms are not fully understood, but impaired autoregulation as well as enhanced vulnerability at the tissue level are thought to play a role.[7] The patients with absent or severely impaired autoregulation may be at high risk of ischemic brain damage if hypotension or increases in ICP occur. If, for example, patients lacking autoregulation undergo secondary surgical procedures for their injuries, even moderate hypotension in the perioperative period could cause critical reductions in $\mathrm{CBF}$.

The association between hypotension and poor outcome in head-injured patients has been well documented.[3,17,18,20] Information from the Traumatic Coma Data Bank indicates that lowered CPP resulting from hypotension or increased ICP is associated with a poor outcome following head injury.[3,17] Pietropaoli, et al.,[27] also found that intraoperative hypotension occurring in severely head injured patients undergoing surgical procedures within 72 hours of admission to the hospital was associated with a significant increase in mortality rates and also a significant decrease in GOS scores compared to those seen in head-injured patients who did not become hypotensive during surgery. Moreover, this same study found that intraoperative hypotension occurred frequently ( $32 \%$ incidence) in this group of head-injured patients. Winchell, et al.,[35] recently reported that transient hypotension occurring in hospitalized head-injured patients was associated with an increased mortality rate and a decreased rate of discharge home. The effects of hypotension on outcome were most dramatic in those patients with minor and moderate head injuries (GCS $>8$ ). Thus, both clinical and experimental studies indicate that the injured brain is more vulnerable to ischemic insults. 
In our patients severe impairment in autoregulation did not appear to be associated with a poor outcome or complications following any surgical procedures. It is likely that more sensitive outcome measures and neuropsychological testing are required to detect many of the subtle deficits that could occur following secondary ischemic damage after minor head injury.[28,29]

Strategies to prevent secondary ischemic damage in head-injured patients with impaired autoregulation could include several approaches. Because low MABP in our patients was clearly associated with worse autoregulation, it seems logical to avoid hypotension and increase CPP, especially during secondary surgical procedures. However, hypertension may also be detrimental to patients lacking autoregulation.[32] Rosner, et al.,[30] have recently shown that maintenance of CPP is associated with improved outcome after severe head injury. Despite the fact that the association between hypotension and worse outcome following head injury is well known, intraoperative hypotension remains relatively common in head-injured patients undergoing surgery.[27] Other options for avoiding secondary ischemic damage in these patients include preoperative or intraoperative autoregulation testing to identify those patients with poor autoregulation and monitoring jugular venous $\mathrm{O} 2$ saturation in affected patients to optimize CPP.[31] Further studies are needed to determine the precise mechanisms responsible for impaired autoregulation after head injury, the time course of the impairment, and to evaluate possible strategies for improvment of the autoregulatory response.

\section{Acknowledgments}

We thank Sheila Byrd, R.T.V., and Anne Moore, R.V.T., for their help with many of the Doppler studies. We also thank all the volunteers and patients who participated in the studies. We thank Nancy Temkin, Ph.D., and Kevin Anstrom for help with the statistical analysis.

\section{References}

1. Aaslid R, Lindegaard KF, Sorteberg W, et al: Cerebral autoregulation dynamics in humans. Stroke 20:45-52, 1989

2. Aaslid R, Newell DW, Stooss R, et al: Assessment of cerebral autoregulation dynamics from simultaneous arterial and venous transcranial Doppler recordings in humans. Stroke 22:1148-1154, 1991

3. Chesnut RM: Secondary brain insults after head injury: clinical perspectives. New Horiz 3:366-375, 1995

4. Cold GE: Cerebral blood flow in acute head injury. The regulation of cerebral blood flow and metabolism during the acute phase of head injury, and its significance for therapy. Acta Neurochir Suppl 49:1-64, 1990

5. Cold GE, Christensen MS, Schmidt K: Effect of two levels of induced hypocapnia on cerebral autoregulation in the acute phase of head injury coma. Acta Anaesthesiol Scand 25:397-401, 1981

6. Cold GE, Jensen FT: Cerebral autoregulation in unconscious patients with brain injury. Acta Anaesthesiol Scand 22:270-280, 1978

7. DeWitt DS, Jenkins LW, Prough DS: Enhanced vulnerability to secondary ischemic insults after experimental traumatic brain injury. New Horiz 3:376-383, 1995 
8. Enevoldsen E: CBF in head injury. Acta Neurochir Suppl 36:133-136, 1986

9. Enevoldsen EM, Jensen FT: Autoregulation and $\mathrm{CO}_{2}$ responses of cerebral blood flow in patients with acute severe head injury. J Neurosurg 48:689-703, 1978

10. Jenkins LW, Lyeth BG, Hayes RL: The role of agonist-receptor interactions in the pathophysiology of mild and moderate head injury, in Hoff J, Anderson T, Cole T (eds): Mild to Moderate Head Injuries. Boston: Blackwell, 1989, pp 47-61

11. Jennett B, Bond M: Assessment of outcome after severe brain damage. A practical scale. Lancet 1:480-484, 1975

12. Jennett B, Snoek J, Bond MR, et al: Disability after severe head injury: observations on the use of the Glasgow Outcome Scale. J Neurol Neurosurg Psychiatry 44:285-293, 1981

13. Larsen FS, Olsen KS, Hansen BA, et al: Transcranial Doppler is valid for determination of the lower limit of cerebral blood flow autoregulation. Stroke 25:1985-1988, 1994

14. Lassen NA: Cerebral blood flow and oxygen consumption in man. Physiol Rev 39:183-238, 1959

15. Lewelt W, Jenkins LW, Miller JD: Autoregulation of cerebral blood flow after experimental fluid percussion injury of the brain. J Neurosurg 53:500-511, 1980

16. Lindegaard KF, Lundar T, Wiberg J, et al: Variations in middle cerebral artery blood flow investigated with noninvasive transcranial blood velocity measurements. Stroke 18:1025-1030, 1987

17. Marmarou A, Ward JD, Young HF, et al: Impact of ICP instability and hypotension on outcome in patients with severe head trauma. J Neurosurg 75 (Suppl):S59-S66, 1991

18. Miller JD, Butterworth JF, Gudeman SK, et al: Further experience in the management of severe head injury. J Neurosurg 54:289-299, 1981

19. Miller JD, Stanek AE, Langfitt TW: Cerebral blood flow regulation during experimental brain compression. J Neurosurg 39:186-196, 1973

20. Miller JD, Sweet RC, Narayan R, et al: Early insults to the injured brain. JAMA 240:439-442, 1978

21. Muizelaar JP, Lutz HA III, Becker DP: Effect of mannitol on ICP and CBF and correlation with pressure autoregulation in severely head-injured patients. J Neurosurg 61:700-706, 1984

22. Muizelaar JP, Ward JD, Marmarou A, et al: Cerebral blood flow and metabolism in severely head-injured children. Part 2: Autoregulation. J Neurosurg 71:72-76, 1989

23. Newell DW, Aaslid R, Douville CM, et al: Comparison of autoregulation and $\mathrm{CO}_{2}$ reactivity in occlusive disease. Stroke 25:748, 1994 (Abstract)

24. Newell DW, Aaslid R, Lam A, et al: Comparison of flow and velocity during dynamic autoregulation testing in humans. Stroke 25:793-797, 1994

25. Overgaard J, Tweed WA: Cerebral circulation after head injury. Part 1. Cerebral blood flow and its regulation after closed head injury with emphasis on clinical correlations. J Neurosurg 41:531-541, 1974 
26. Paulson OB, Strandgaard S, Edvinsson L: Cerebral autoregulation. Cerebrovasc Brain Metab Rev 2:161-192, 1990

27. Pietropaoli JA, Rogers FB, Shackford SR, et al: The deleterious effects of intraoperative hypotension on outcome in patients with severe head injuries. J Trauma 33:403-407, 1992

28. Rimel RW, Giordani B, Barth JT, et al: Disability caused by minor head injury. Neurosurgery 9:221-228, 1981

29. Rimel RW, Giordani B, Barth JT, et al: Moderate head injury: completing the clinical spectrum of brain trauma. Neurosurgery 11:344-351, 1982

30. Rosner MJ, Rosner SD, Johnson AH: Cerebral perfusion pressure: management protocol and clinical results. J Neurosurg 83:949-962, 1995

31. Sheinberg M, Kanter MJ, Robertson CS, et al: Continuous monitoring of jugular venous oxygen saturation in head-injured patients. J Neurosurg 76:212-217, 1992

32. Simard JM, Bellefleur M: Systemic arterial hypertension in head trauma. Am J Cardiol 63:32C-35C, 1989

33. Strebel S, Lam AM, Matta B, et al: Dynamic and static cerebral autoregulation during isoflurane, desflurane, and propofol anesthesia. Anesthesiology 83:66-76, 1995

34. Tiecks FP, Lam AM, Aaslid R, et al: Comparison of static and dynamic cerebral autoregulation measurements. Stroke 26:1014-1019, 1995

35. Winchell RJ, Simons RK, Hoyt DB: Transient systolic hypotension. A serious problem in the management of head injury. Arch Surg 131:533-539, 1996

Manuscript received January 3, 1996.

Accepted in final form September 26, 1996.

This work was supported by Clinician Investigator Development Award No. 1K08 NS 01596901 and National Institutes of Health Program project in head injury grant No. 1 P50 NS 30305-01 (D.W.N.), and also by the Department of Neurology, University of Heidelberg, Heidelberg, Germany (E.C.J.).

Address for Dr. Jünger: University of Heidelberg, Heidelberg, Germany.

Address reprint requests to: David W. Newell, M.D., Department of Neurological Surgery, Harborview Medical Center, 325 9th Avenue, Seattle, Washington 98104. 